\title{
On origin of near-axis volcanism and faulting at fast spreading mid-ocean ridges
}

\author{
Yuri Fialko* \\ Seismological Laboratory, California Institute of Technology, Pasadena, CA, USA
}

Received 5 January 2001; received in revised form 30 April 2001; accepted 14 May 2001

\begin{abstract}
At fast and superfast spreading mid-ocean ridges, such as the East Pacific Rise, a plate boundary is defined by a narrow (tens to hundreds of meters wide) neovolcanic zone within which the bulk of the upper oceanic crust is created. However, detailed near-bottom observations indicate that the volcanic construction may occasionally persist several kilometers off of the ridge axis. It has been proposed that off-axis volcanism manifests tapping of a wide melting region that supplies magma to the ridge axis, or spatial migration of magmatic sources in the crust and upper mantle. We demonstrate that off-axis eruptions may be a natural consequence of variations in magma supply rate even if the ridge axis is stationary in space, and the magma delivery is perfectly focussed at the ridge axis. Theoretical modeling and field observations indicate that off-axis volcanism may result from magma emplacement in sills that propagate toward the surface after their characteristic horizontal size exceeds their emplacement depth. Volcanic construction and faulting due to sill intrusions may contribute to the formation of abyssal hills, arguably the most abundant relief form on Earth. (C) 2001 Elsevier Science B.V. All rights reserved.
\end{abstract}

Keywords: mid-ocean ridges; magmas; sills; models; abyssal hills

\section{Introduction}

At the fast spreading East Pacific Rise (EPR), most of the upper oceanic crust is accreted in a relatively narrow (several tens to several hundreds of meters wide) neovolcanic zone, as inferred from the seafloor morphology [1,2], hydrothermal activity [3,4], and lava geochemistry [5,6]. Geomorphic expression of the neovolcanic zone ap-

\footnotetext{
* Present address: Institute of Geophysics and Planetary Physics, Scripps Institute of Oceanography, University of California San Diego, La Jolla, CA, USA.

Tel.: +1-858-822-5028; E-mail: fialko@radar.ucsd.edu
}

proximately coincides with the lateral extent of a shallow magma lens beneath the ridge axis. Seismic imaging of the sub-axial magma lens suggests that the latter resides at depth of $\sim 1-2 \mathrm{~km}$ below the seafloor, and is about $1-2 \mathrm{~km}$ wide, and a few tens to a few hundreds of meters thick [7-9]. The shallow magma lens is believed to be a primary source of basalts comprising the upper oceanic crust at the fast spreading mid-ocean ridges (e.g., [10]).

While it is generally accepted that the axial neovolcanic zone is the main locus of magmatic construction at the EPR, detailed ocean floor surveys including visual observations from submersibles and rock sampling along the northern EPR reveal 
that volcanic activity may sometimes occur several kilometers from the ridge axis. The inferred off-axis volcanic activity is expressed in younglooking lava fields and conspicuous pillow ridges and mounds $[2,6]$ that can be several tens of meters high and are often associated with fault scarps and fissure swarms [11]. The usual absence of pillow ridges in the axial crest area suggests that they are autochthonous volcanic features, and are not simply transported laterally from the neovolcanic zone via plate spreading. The off-axis origin of pillow ridges and 'disconformant' lava flows is corroborated by their asymmetry with respect to the axial neovolcanic zone [6], radioisotope dating [12], geochemical dissimilarity to the on-axis lavas $[6,13]$, and near-bottom gravity measurements that have been interpreted as indicating the presence of underlying feeder conduits [14]. These observations are not readily explained by the existing models of crustal accretion at spreading centers. It has been proposed that the off-axis volcanism may manifest occasional 'leaking' of melt from a wide production area beneath the ridge axis $[13,15]$, a spatial migration of regions of transient magma accumulation in the crust or upper mantle [6,11], or tapping of the edges of the shallow magma lens [6]. If so, particular physical mechanisms that might be responsible for the observed eruptive behavior (for example, the onset and cessation of the off-axis volcanism within several kilometers of the ridge axis, apparent association of eruption sites with faulting, etc.) remain enigmatic.

Near-axis faulting and volcanic construction are thought to be the cause of undulations of the seafloor topography that extend parallel to the ridge axis with an average spacing of a few kilometers in the ridge spreading direction $[1,16]$. These topographic undulations (known as 'abyssal hills') cover virtually all of the ocean floor, and are arguably the most abundant relief form on Earth [17]. Ever since the discovery of abyssal hills their origin has been a subject of considerable debate. Proposed models for the development of abyssal hills include off-axis faulting, episodic on- or off-axis volcanism, or some combination of these (for a summary, see, e.g., [17]). Morphologically, abyssal hills are defined by steep slopes that are interpreted as inwardand outward-dipping normal faults $[1,17]$. Inward-dipping normal faults are ubiquitous on slow spreading mid-ocean ridges, where they accommodate up to $10-20 \%$ of extension associated with plate spreading [18,19]. Outward-dipping normal faults are, however, almost unique to fast and intermediate spreading ridges. Establishing their origin is essential for understanding the formation of the abyssal hills. It has been suggested that outward-dipping faults can form at fast spreading ridges because of a less dramatic thickening of the brittle layer away from the ridge axis compared to slow spreading ridges [20,21]. However, it is unclear whether the reduced variability in the thickness of the brittle layer at high spreading rates is sufficient to favor the formation of both inward- and outward-dipping faults. Detailed modeling of the near-axis thermal regime suggests that the rate at which the brittle layer thickens off-axis may not be very different at fast and slow spreading ridges (e.g., [22]). In addition, a significant horizontal extension (i.e., capable of producing large-scale normal faulting) near the ridge axis is not easily reconciled with a robust magma supply and the presence of a steady-state melt reservoir at the fast spreading mid-ocean ridges. This is because a readily available melt in a sub-axial magma lens likely ensures that the stress state in the adjacent brittle crust is close to lithostatic [23,24]. Measurements of throw on normal faults indicate that the outward-dipping faults form quite close to the ridge axis $[17,25]$. These arguments suggest that models of formation of abyssal hills that appeal to offaxis normal faulting due to tectonic extension alone may need to be revised.

We propose that many of the observed morphologic features at fast spreading mid-ocean ridges (in particular, the off-axis faulting and eruptions) may result from episodic emplacement of magma sills (i.e., sub-horizontal sheet intrusions) beneath the ridge axis. While it is well established that magma transport in the upper brittle crust is predominantly sub-vertical and accommodated by dike intrusions (e.g., $[19,26]$ ), sporadic increases in magma supply to the ridge axis may temporarily overwhelm the far-field ex- 
tensional stress field imposed by plate separation [27]. In this case, repeated dike injections are expected to reset the least compressive stress in the upper crust from horizontal to vertical, and continued magma supply may favor subsequent magma intrusions in sills. Sills might form in the result of lateral 'break-outs' of a shallow magma lens, or magma emplacement in horizontal sheets at deeper levels in the crust. While a complete understanding of the physical processes governing magma intrusions in horizontal sheets beneath the ridge axis is still lacking, field observations (in particular, in the Oman ophiolite, which is thought to be a fossil analog of a fast spreading ridge [28]) suggest that sill intrusions in the middle to lower oceanic crust may be a highly nonunique phenomenon [27,28]. Because horizontal intrusions may play an important role in the accretion of the middle and lower oceanic crust, it is instructive to consider mechanical aspects and consequences of magma propagation in sills.

\section{Theoretical modeling and observations of climbing sills}

Large aspect ratios of mafic dikes and sills, as well as short time scales associated with their formation allows one to treat them as fluid-pressurized cracks in an elastic medium [29-31]. The theory of fluid-filled cracks in an infinite elastic body is well established [29,32,33]. Assuming a lithostatic stress state, a sill is expected to propagate in its own plane by hydraulically fracturing the host rocks. However, as the half-length of the sill $L$ becomes comparable to and exceeds the sill emplacement depth $H$, the intrusion will increasingly interact with the free surface (i.e., the ocean floor) [34-36]. The effects of such an interaction are twofold. First, an increase in the intrusion size-to-depth ratio $L / H$ concentrates deformation in the intrusion roof. Second, stress perturbations due to the presence of the free surface may cause the sill to rotate its propagation trajectory and turn toward the surface. Fig. 1 shows a rotation of the maximum tensile stress at the intrusion tip as predicted by analytic models of horizontal magma-filled cracks [35,36]. Results shown in

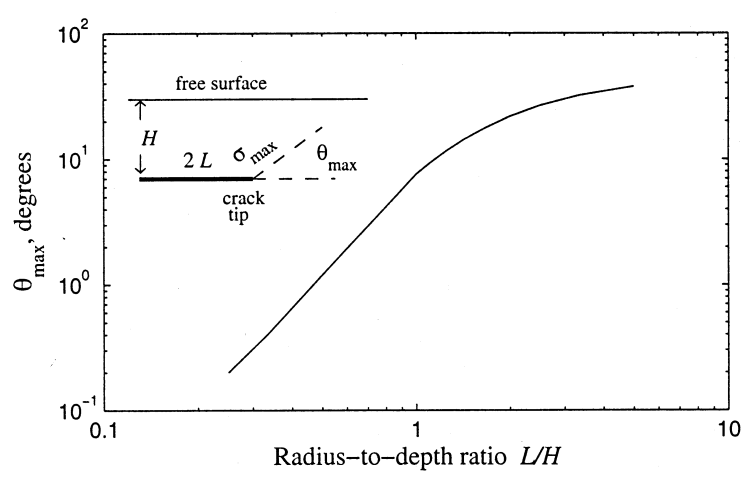

Fig. 1. Orientation of the maximum tensile stress $\sigma_{\max }$ at the tip of a uniformly pressurized circular crack as a function of the crack length-to-depth ratio $L / H . \theta_{\max }$ is the angle between the crack plane and the plane along which the maximum tensile stress $\sigma_{\max }$ is acting.

Fig. 1 correspond to a uniformly pressurized penny-shaped crack in an isotropic elastic halfspace. The stress rotation at the tip of a two-dimensional (2-D) plain strain crack (e.g., corresponding to a sub-axial magma lens having along-axis extent that greatly exceeds its acrossaxis size) is similar to that shown in Fig. 1 [37]. Available analytic solutions correspond to planar cracks, and they become inapplicable when a crack starts to deviate from its original plane. To calculate the actual trajectory of a magmadriven sill and the concomitant perturbations in the large-scale stress field, the sill growth is simulated using a boundary element model that explicitly accounts for the effects of the free surface [38,39].

In the models presented below, a 2-D magmadriven crack is approximated by a number of dislocations (displacement discontinuities) that on average satisfy prescribed stress boundary conditions at the crack surface [24,39]. The crack growth is simulated by adding boundary elements at the crack tip in a direction that maximizes tensile stresses resolved on a prospective crack increment. Because of the linearity of the governing equations of theory of elasticity, the crack trajectory is calculated using only stress perturbations due to the excess magma pressure (i.e., total stress minus lithostatic stress). For simplicity, viscous pressure losses associated with magma flow inside 
the crack [29,31], thermal effects [26], and details of inelastic failure at the crack tip [39] are neglected. The sill growth is considered as a sequence of equilibrium states in which magma completely comes to rest. Note that because our calculations are time-independent, the results are insensitive to variations in magma viscosity and crystal content, as long as the magma is sufficiently mobile on a timescale of the intrusion emplacement. Magmas having crystal contents of less than about $30 \%$ are likely to satisfy the latter requirement (e.g., [10]). The ambient stress is assumed to be lithostatic, with the vertical component of stress gradient of $28 \mathrm{MPa} / \mathrm{km}$, and the excess magma pressure inside a sill is hydrostatic, and equals $8 \mathrm{MPa}$. Above the depth of $1 \mathrm{~km}$ the excess magma pressure is assumed to linearly decrease with depth to $0 \mathrm{MPa}$ at the seafloor to mimic the effects of negative magma buoyancy in the uppermost crust [40]. Fig. 2 shows the calculated sill trajectory for an initial emplacement depth of $2 \mathrm{~km}$. The boundary element size (which defines the intrusion increment size) used in the calculations is $10 \mathrm{~m}$, and the initial intrusion length is $100 \mathrm{~m}$. As one might expect, the sill continues to propagate horizontally when its half-length $L$ is small compared to its depth $H$. For $L / H>1$, however, the sill begins to turn toward the surface (Fig. 2a). Because the free surface amplifies the stress concentration at the crack tip and increases the crack aperture behind the tip [34], one may anticipate that at this point the sill growth may become essentially asymmetric (e.g., a statistically longer sill arm is likely to 'win out', and preferentially propagate toward the surface). In the model shown in Fig. 2 , the left sill tip is 'frozen' as the intrusion reaches the ratio $L / H=1$. Continued sill propagation at the other end ultimately results in an 'eruption' at a distance of about three times the initial emplacement depth (Fig. 2c). The calculated dip angle of the intrusion is in a good agreement with predictions of analytic models for a horizontal fluid-filled crack ([34,41], Fig. 1). We point out that if the host rocks deform essentially elastically, our solution is self-similar. That is, given an arbitrary emplacement depth, the intrusion geometry can be inferred from Fig. 2 by simple linear rescaling of the vertical and horizon-
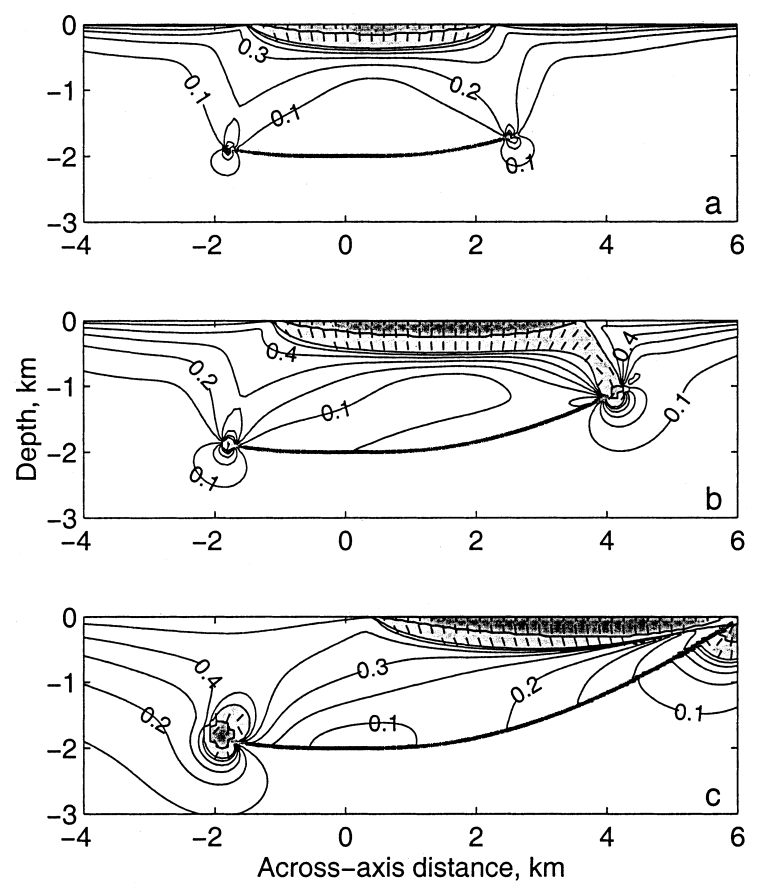

Fig. 2. Boundary element simulation of a 2-D magma-driven sill (thick solid line) in an elastic half-space. Zero depth corresponds to the seafloor. The excess magma pressure is $8 \mathrm{MPa}$ between 1 and $2 \mathrm{~km}$ depth, and linearly decreases to $0 \mathrm{MPa}$ between $1 \mathrm{~km}$ and the seafloor. Contour lines denote the ratio of shear stress to the effective normal stress (normal stress minus hydrostatic pore pressure) on optimally oriented failure planes, assuming a coefficient of friction of 0.6. Lightand dark-shaded areas denote regions of potential shear and tensile failure, respectively. Ticks show the orientation of the maximum compressive stress in the absence of inelastic deformation.

tal axes. In the absence of inelastic deformation off of the sill plane, the sill propagation trajectory is also independent of the absolute value of the excess magma pressure. Several factors may cause deviation of the actual propagation path of a sill from calculations shown in Fig. 2. For example, the presence of a transverse anisotropy of the host rock strength may stabilize the sill growth in its own plane, while a corresponding vertical anisotropy (e.g., in a sheeted dike section) may enhance the tendency for turning toward the surface. Climb angles of sills that are steeper than those predicted by Figs. 1 and 2 may also result from sill propagation into a region of an increasing horizontal extension (e.g., due to plate cooling 
and contraction), and non-uniform magma pressure distribution inside the sill (e.g., due to a viscous flow of magma) [34].

That the sill emplacement may give rise to a sub-vertical magma transport has been known from field observations for a long time. In continental settings, the tendency of large sills to produce 'saucer-like shapes' or 'peripheral dikes' is well documented [42,43]. de Voogd et al. [44] interpret seismic reflection data from the Death Valley, California (USA), as indicating a sill-like magma body that propagated toward the Earth surface at a moderately dipping angle from depth of about $15 \mathrm{~km}$, and fed a surface eruption. Ample empirical evidence for curving of initially horizontal fluid-driven cracks toward the Earth surface is also lent by experimental and industrial hydrofractures [34,45]. Fig. 3 shows one example from the Troodos ophiolite (Cyprus) of a tabular magma intrusion cutting at a low angle through shallow volcanic rocks (lava flows and pillows). The preserved horizontal layering of the shallow volcanics indicates that the dipping magma intrusion is in its original emplacement position. The overall similarity between the results of theoretical modeling (Fig. 2c) and the gently dipping intrusion in Fig. 3 indicates that the latter may represent a near-surface exposure of a climbing sill.

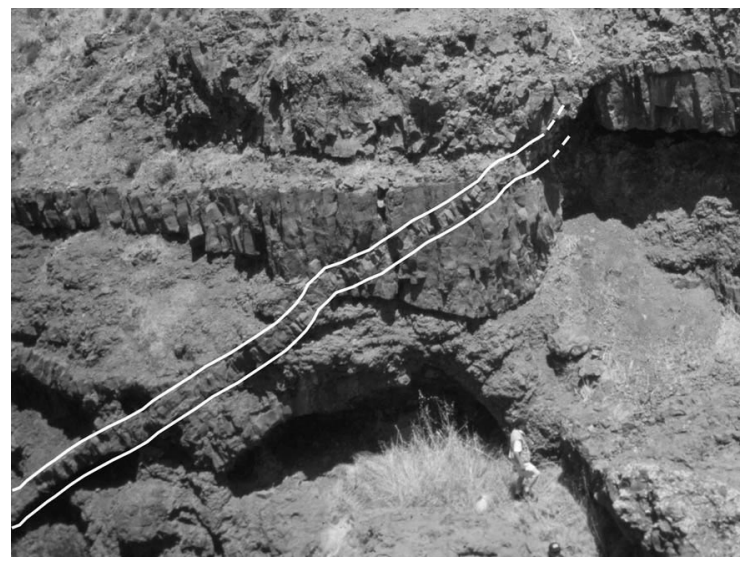

Fig. 3. An outcrop exposure of a shallowly dipping magma sheet (outlined) that intrudes the upper volcanic layer (lava flows and pillow basalts) in the Troodos ophiolite, Cyprus. Note a person at the bottom of the figure for scale. There is an overall agreement of the intrusion geometry (in particular, the dip angle) with theoretical predictions in Fig. 2.

\section{Discussion}

The model shown in Fig. 2 may explain several peculiar features of the off-axis volcanism at the EPR. First, the model predicts that the onset of the off-axis volcanic activity is controlled by the sill emplacement depth. At the EPR, most of the off-axis volcanism occurs within several kilometers from the ridge axis $[2,6,46]$. This is consistent with sill emplacement at depths corresponding to (or somewhat greater than) the depth of a sub-axial magma lens. Second, the model implies that essentially two-dimensional sills (i.e., sills having an along-axis extent that greatly exceeds their across-axis dimension, e.g., [47]) may give rise to off-axis fissure eruptions that might contribute to the formation of pillow ridges, while asymmetrically growing penny-like sills are likely to produce short (and perhaps arcuate) fissures, and feed isolated lava flows. Note that the asymmetry of eruptions with respect to the ridge axis is an intrinsic feature of the model that stems from a non-linear intrusion interaction with the free surface. Emplacement of climbing sills may also contribute to the observed off-axis increases in the thickness of the seismic layer 2A [48].

Reston et al. [49] report observations of multiple reflectors in the Cretaceous oceanic crust in the North-West Pacific that dip toward the inferred (paleo) ridge axis at low $\left(20-30^{\circ}\right)$ angles, and suggest that these reflectors might represent lithological layering, or low-angle detachment faults in the lower and middle crust. However, the mechanics of either of the proposed processes is not understood. We point out that the geometry of crustal reflectors imaged by seismic studies [49] is intriguingly similar to that of climbing sills, as predicted by theoretical models (Fig. 2), and observed in the field (Fig. 3). If the shallowly dipping reflectors are of magmatic origin, acoustic impedance contrasts required to explain seismic reflections might be due to chemical differentiation (e.g., crystal settling) during magma crystallization within the intrusion, and/or subsequent hydrothermal alteration. Note that the emplacement and crystallization of sill-like magma bodies ('magmatic underplating') is believed to be a primary cause of high reflectivity of the middle and 
lower continental crust (in particular, in active continental rift zones) (e.g., [50]). Yet, it is unclear whether the required impedance contrasts may be produced in the oceanic crust in the result of emplacement of relatively thin sheet intrusions (e.g., having thickness of the order of several meters).

Lateral magma transport in sub-axial climbing sills has important implications for the the observed geochemical dissimilarity between the onaxis and off-axis lavas [6,13]. In particular, compositional differences between the on- and off-axis volcanics may be indicative of an incomplete mixing in a shallow magma lens during periods of an increased magma supply. More specifically, offaxis eruptions of fractionated melts may result from magma withdrawal from distal ends of a shallow lens [6] during lateral break-outs. Alternatively, incomplete mixing of a newly arrived unfractionated magma may give rise to off-axis eruptions of more primitive melts. For individual sill intrusions occurring at greater depths (i.e., in the middle to lower crust), magmas that erupt offaxis may never enter the shallow sub-axial reservoir. Spiegelman and Reynolds [13] present evidence for the depleted signatures of basalts that erupted off-axis at the EPR at $12^{\circ} \mathrm{N}$, and argue that this depletion is most consistent with models of a porous melt flow in a passively upwelling viscous mantle. However, a possibility of lateral redistribution of melt in the upper brittle crust suggested by this study implies that shallow processes may be the controlling factor for the observed across-strike geochemical variations of the erupted basalts. The essentially non-steady nature of the processes that presumably give rise to the intrusion of sills beneath the ridge axis (e.g., episodic purging of the shallow magma lens during magmatic surges) may generate the complexity in geochemical signatures of the on-axis versus offaxis volcanics noted in several areas along the EPR [15].

For sills that propagate toward the surface and erupt, magma withdrawal from the source will eventually result in sill deflation and subsidence. This subsidence is likely to be accommodated along the established magma conduit, which may give rise to a deformation pattern that resembles inward-dipping normal faulting. Both in- ward- and outward-dipping normal faults may be produced during sill growth as a result of failure of the intrusion roof. Inelastic deformation of the host rocks predicted by our model for the excess magma pressure of $8 \mathrm{MPa}$ (on a high end by theoretical estimates) is shown in Fig. 2. Contours in Fig. 2 denote the ratio of shear stress to the effective normal stress (i.e., the difference between the normal stress and the hydrostatic pore pressure) resolved on planes that are optimally oriented for failure. Assuming a Mohr-Coulomb failure envelope, slip on optimally oriented planes is predicted when this ratio exceeds a coefficient of friction $\mu$ (e.g., [51]). Shear failure is expected to occur along one of the planes inclined at an angle $\left(\pi / 2-\arctan \mu^{-1}\right) / 2$ with respect to the maximum compressive stress axis (see ticks in Fig. 2). The modeling results show that sill emplacement may give rise to outward-dipping or nearly vertical normal faults, given a sufficiently high excess magma pressure. Increases in the deviatoric horizontal extension off the ridge axis would require smaller excess magma pressure for sill-induced faulting. We point out that the large-scale shear deformation associated with growing sills is documented by field observations of the eroded intrusions in the continental crust [52], and has been recently imaged by space geodetic observations in the Galapagos volcanoes [53]. The model shown in Fig. 2 is meant to demonstrate the overall qualitative behavior during sill intrusions, and it does not explicitly consider inelastic deformation. Faulting at the sill periphery may affect the sill growth by modifying the near-tip stress field and reducing the excess magma pressure. A net effect could be the intrusion propagation arrest. This implies that sill-fed eruptions might require sufficiently low excess magma pressures (i.e., to avoid peripheral faulting). For a given excess magma pressure, peripheral faulting is likely to be progressively suppressed for sill intrusions at greater depths, as the Mohr-Coulomb failure shear stress linearly increases with confining pressure.

The faulting mechanism depicted in Fig. 2 (essentially, the sill-induced horst formation) provides an alternative to the commonly envisaged tectonic origin of the outward-dipping normal faults at the fast spreading mid-ocean ridges. 
The onset of large-scale faulting at the EPR is quite sharp at $1-2 \mathrm{~km}$ from the axis [21]. This broadly agrees with the model prediction for the initiation of faulting at distances of the order of the sill depth (Fig. 2b). The inferred decrease in the number of the outward-dipping faults with a decreasing spreading rate [21] is consistent with an overall decrease in the magma supply, disappearance of a steady-state subaxial magma lens, and a reduced frequency of magmatic surges [27] that render magma intrusion in sills unlikely. Our calculations (such as those illustrated in Fig. 2) show that sills having excess magma pressure of several megapascals and length of several kilometers will have thickness of the order of several meters. If sill-induced faulting plays a role in the formation of abyssal hills on the EPR, the observed throws on the near-axis faults of a few tens of meters $[1,17]$ might be produced by several generations of sill intrusions. Alternatively, the sill-induced faults might be re-activated in the presence of the off-axis deviatoric extension (e.g., during periods of decreased magma supply to the ridge axis). The off-axis extension may be a predominant mechanism for the growth of the inward-dipping faults, as evidenced by a continued development of the latter over distances of the order of several tens of kilometers away from the ridge axis [21]. The outward-dipping normal faults seem to accumulate most of their throw within a few kilometers from the ridge axis [17], consistent with the mechanism discussed above, although recent observations around $8-10^{\circ} \mathrm{N}$ at the EPR indicate that both the inward- and outward-dipping faults may remain active within several tens of kilometers from the axis [25]. Therefore, the observed seafloor topography may be a result of some complex interaction between magmatic construction, magma-induced deformation, and tectonic extension. An overall strain partitioning between 'magmatic' and 'tectonic' contributions to the nearaxis crustal deformation is an outstanding problem that needs to be addressed in a future work.

\section{Conclusions}

Field observations in ophiolite complexes dem- onstrate that magmatic accretion at the fast and intermediate spreading ridges may involve episodic intrusions of sills (horizontal magma sheets). Although particular physical mechanisms that give rise to sill emplacement beneath the ridge axis are not fully understood, observations and theoretical arguments suggest that the emplacement of horizontal magma intrusions may result from re-orientation of the least compressive stress from horizontal to vertical, e.g., during periods of an increased melt supply to the crust from the sub-axial source region. Numerical modeling of the sill growth in an elastic half-space under lithostatic stress conditions indicates that after reaching a length-to-depth ratio of the order of unity, sills no longer tend to propagate in their own planes, and are likely to climb to higher stratigraphic levels. This effect is a result of the intrusion interaction with the stress-free surface (such as the ocean floor). Given sufficient magma supply, a continued sill propagation may give rise to magma eruptions at the off-axis distances of about three times the initial emplacement depth. This mechanism may be responsible for the observed manifestations of volcanism within several kilometers from the ridge axis at the EPR. Analysis of deformation associated with emplacement of large sills indicates that reasonable fracture criteria may be exceeded in the intrusion roof for the excess magma pressures of the order of several megapascals. The resulting failure and uplift of the overlying strata may be accommodated along steep outward-dipping normal faults, with throws on the faults of the order of the intrusion thickness. This process may result in the formation of sill-induced horsts, and, in the presence of many generations of magma intrusions, contribute to the observed near-axis faulting, and formation of abyssal hills at the fast spreading mid-ocean ridges.

\section{Acknowledgements}

The author thanks Ken Macdonald, and two anonymous reviewers for their comments, and Ed Stolper and Paul Azimow for discussions of an early version of the manuscript. This work was 
supported by NSF Grant EAR-9980664 and a post-doctoral fellowship at Caltech.[SK]

\section{References}

[1] P. Lonsdale, Structural geomorphology of a fast spreading ridge crest: The East Pacific Rise near $8^{\circ} 45^{\prime} \mathrm{S}$, Mar. Geophys. Res. 3 (1977) 251-293.

[2] D. Fornari, R. Haymon, M. Perfit, T. Gregg, M. Edwards, Axial summit trough of the east pacific rise $9^{\circ}$ $10^{\circ} \mathrm{N}$ : Geological characteristics and evolution of the axial zone on fast spreading mid-ocean ridges, J. Geophys. Res. 103 (1998) 9827-9855.

[3] R.M. Haymon et al., Hydrothermal vent distribution along the East Pacific Rise crest $\left(9^{\circ} 09^{\prime}-54^{\prime} \mathrm{N}\right)$ and its relationship to magmatic and tectonic processes on fast spreading mid-ocean ridges, Earth Planet. Sci. Lett. 104 (1991) 513-534.

[4] K.L. Von Damm et al., Short term chemical and temperature changes in seafloor hydrothermal vent at $9^{\circ} 46.5^{\prime} \mathrm{N}$ EPR following a volcanic eruption, Nature 375 (1995) 4750.

[5] J. Reynolds, C. Langmuir, J. Bender, K. Kastens, W.B.F. Ryan, Spatial and temporal variability in the geochemistry of basalts from the East Pacific Rise, Nature 359 (1992) 493-499.

[6] M.R. Perfit et al., Small-scale spatial and temporal variations in mid-ocean ridge crest magmatic processes, Geology 22 (1994) 375-379.

[7] G.M. Kent, A.J. Harding, J.A. Orcutt, Evidence for a smaller magma chamber beneath the East Pacific Rise at $9^{\circ} 30^{\prime} \mathrm{N}$, Nature 344 (1990) 650-653.

[8] R.S. Detrick et al., Seismic structure of the southern East Pacific Rise, Science 259 (1993) 499-503.

[9] G. Kent et al., Evidence from three-dimensional seismic reflectivity images for enhanced melt supply beneath midocean-ridge discontinuities, Nature 406 (2000) 614-618.

[10] J. Sinton, R. Detrick, Midocean ridge magma chambers, J. Geophys. Res. 97 (1992) 197-216.

[11] M.R. Perfit, and J. Chadwick, Magmatism at mid-ocean ridges; constraints from volcanological and geochemical investigations, in: W.R. Buck, P.T. Delaney, J.A. Karson, Y. Lagabrielle (Eds.), Geophys. Monogr. 106 (1998) 59115.

[12] S.J. Goldstein, M.R. Perfit, R. Batiza, D.J. Fornari, Temporal variations in East Pacific Rise magmatic activity based on U-series dating of basalts, Nature 367 (1994) 157-159.

[13] M. Spiegelman, J.R. Reynolds, Combined dynamic and geochemical evidence for convergent melt flow beneath the East Pacific Rise, Nature 402 (1999) 282-285.

[14] J.R. Cochran, D.J. Fornari, B.J. Coakley, R. Herr, M.A. Tivey, Continuous near-bottom gravity measurements made with a BGM-3 gravimeter in DSV Alvin on the
East Pacific Rise crest near $9^{\circ} 31^{\prime} \mathrm{N}$ and $9^{\circ} 50^{\prime} \mathrm{N}$, J. Geophys. Res. 104 (1999) 10841-10861.

[15] M.R. Perfit, Molten rocks in motion, Nature 402 (1999) 245-247.

[16] M. Edwards, D. Fornari, A. Malinverno, W. Ryan, J. Madsen, The regional tectonic fabric of the East Pacific Rise from $12^{\circ} 50^{\prime} \mathrm{N}$ to $15^{\circ} 10^{\prime} \mathrm{N}$, J. Geophys. Res. 96 (1991) 7995-8017.

[17] K.C. Macdonald, P.J. Fox, R.T. Alexander, R. Pocklany, P. Gente, Volcanic growth faults and the origin of abyssal hills on the flanks of the East Pacific Rise, Nature 380 (1996) 125-129.

[18] K. Macdonald, B. Luyendyk, Deep-tow studies of the structure of the Mid-Atlantic Ridge crest near latitude $37^{\circ} \mathrm{N}$, Geol. Soc. Am. Bull. 88 (1977) 621-636.

[19] J. Karson et al., Along-axis variations in sea-floor spreading in the Mark area, Nature 328 (1987) 681-685.

[20] S.M. Carbotte, K.C. Macdonald, Causes of variation in fault-facing direction on the ocean-floor, Geology 18 (1990) 749-752.

[21] K.C. Macdonald, Linkages between faulting, volcanism, hydrothermal activity and segmantation on fast spreading centers, in faulting and magmatism at mid-ocean ridges, in: W.R. Buck, P.T. Delaney, J.A. Karson, Y. Lagabrielle (Eds.), Geophys. Monogr. 106 (1998) 27-58.

[22] T.J. Henstock, A..W. Woods, R.S. White, The accretion of oceanic crust by episodic sill intrusion, J. Geophys. Res. 98 (1993) 4143-4161.

[23] T. Parsons, G.A. Thompson, The role of magma overpressure in suppressing earthquakes and topography: Worldwide examples, Science 253 (1991) 1300-1302.

[24] A.M. Rubin, Dike-induced faulting and graben subsidence in volcanic rift zones, J. Geophys. Res. 97 (1992) 1839-1858.

[25] L. Crowder, K. Macdonald, New constraints on the width of the zone of active faulting on the East Pacific Rise $8^{\circ} 30^{\prime} \mathrm{N}-10^{\circ} 00^{\prime} \mathrm{N}$ from sea beam bathymetry and SeaMARC II side-scan sonar, Mar. Geophys. Res. 21 (2000) 513-527.

[26] Y.A. Fialko, A.M. Rubin, Thermodynamics of lateral dike propagation: Implications for crustal accretion at slow-spreading mid-ocean ridges, J. Geophys. Res. 103 (1998) 2501-2514.

[27] B. Ildefonse, A. Nicolas, F. Boudier, Evidence from the Oman ophiolite for sudden stress changes during melt injection at oceanic spreading centers, Nature 366 (1993) 673-675.

[28] P.B. Kelemen, K. Koga, N. Shimizu, Geochemistry of gabbro sills in the crust-mantle transition zone of the Oman ophiolite: Implications for the origin of the oceanic lower crust, Earth Planet. Sci. Lett. 146 (1997) 475-488.

[29] J.R. Lister, R.C. Kerr, Fluid-mechanical models of crack propagation and their application to magma transport in dykes, J. Geophys. Res. 96 (1991) 10049-10077.

[30] A.M. Rubin, Dikes vs diapires in viscoelastic rock, Earth Planet. Sci. Lett. 119 (1993) 641-659.

[31] Y.A. Fialko, A.M. Rubin, What controls the along-strike 
slopes of volcanic rift zones?, J. Geophys. Res. 104 (1999) 20007-20020.

[32] D.A. Spence, P. Sharp, Self-similar solutions for elastodynamic cavity flow, Proc. R. Soc. London A 400 (1985) 289-313.

[33] Y.M. Khazan, Y.A. Fialko, Fracture criteria at the tip of fluid driven cracks in the Earth, Geophys. Res. Lett. 22 (1995) 2541-2544.

[34] D.D. Pollard, G. Holzhausen, On the mechanical interaction between a fluid-filled fracture and the Earth's surface, Tectonophysics 53 (1979) 27-57.

[35] V.G. Guterman, Y.A. Fialko, Y.M. Khazan, Dome structures over sill-like crustal structures: A numerical model of preseismic uplift. 1, Geophys. J. (Engl. tr.) 16 (1996) 209-226.

[36] Y. Fialko, Y. Khazan, M. Simons, Deformation due to a pressurized horizontal circular crack in an elastic halfspace, with applications to volcano geodesy, Geophys. J. Int. (2001) in press.

[37] F. Erdogan, Bonded dissimilar materials containing cracks parallel to the free surface, Eng. Frac. Mech. 3 (1971) 231-240.

[38] S.L. Crouch, A.M. Starfield, Boundary Element Methods in Solid Mechanics, Allen and Unwin, Boston, MA, 1983, $322 \mathrm{pp}$.

[39] Y.A. Fialko, A.M. Rubin, Numerical simulation of high pressure rock tensile fracture experiments: Evidence of an increase in fracture energy with pressure?, J. Geophys. Res. 102 (1997) 5231-5242.

[40] M.P. Ryan, Neutral buoyancy and the structure of midocean ridge magma reservoirs, J. Geophys. Res. 98 (1993) 22321-22338.

[41] V.G. Guterman, Y.A. Fialko, Y.M. Khazan, Dome structures over sill-like crustal intrusions: A numerical model of preseismic uplift. 2, Geophys. J. (Engl. tr.) 16 (1997) 543-554.

[42] D.D. Pollard, A.M. Johnson, Mechanics of growth of some laccolithic intrusions in the Henry Mountains, Utah, I; field observations, Gilbert's model, physical properties and flow of the magma, Tectonophysics 18 (1973) 261-309.

[43] E.H. Francis, Emplacement mechanism of late Carboniferous tholeiite sills in northern Britain, J. Geol. Soc. London 139 (1982) 1-20.

[44] B. de Voogd et al., Death Valley bright spot: A midcrustal magma body in the southern Great Basin, California?, Geology 14 (1986) 64-67.

[45] Y. Du, A. Aydin, L. Murdoch, Incremental growth of a shallow hydraulic fracture at a waste remediation site, Oakbrook, Illinois from inversion of elevation changes, Int. J. Rock Mech. Min. Sci. Geomech. Abstr. 30 (1993) 1273-1279.

[46] R. Alexander, K. Macdonald, Small off-axis volcanoes on the East Pacific Rise, Earth Planet. Sci. Lett. 139 (1996) 387-394.

[47] S. Singh, G. Kent, J. Collier, A. Harding, J. Orcutt, Melt to mush variations in crustal magma properties along the ridge crest at the southern East Pacific Rise, Nature 394 (1998) 874-878.

[48] A.J. Harding, G.M. Kent, J.A. Orcutt, A multichannel seismic investigation of the upper crustal structure at $9^{\circ} \mathrm{N}$, on the East Pacific Rise: Implications for crustal accretion, J. Geophys. Res. 98 (1993) 13,925-13,944.

[49] T. Reston, C. Ranero, I. Belykh, The structure of Cretaceous oceanic crust of the NW Pacific: Constraints on processes at fast spreading centers, J. Geophys. Res. 104 (1999) 629-644.

[50] H. Thybo, P. Maguire, C. Birt, E. Perchuc, Seismic reflectivity and magmatic underplating beneath the Kenya Rift, Geophys. Res. Lett. 27 (17) (2000) 2745-2748.

[51] J. Byerlee, Friction of rock, Pure Appl. Geophys. 116 (1978) 615-626.

[52] C.E. Corry, Laccoliths: mechanism of emplacement and growth, Geol. Soc. Am. Spec. Pap. 220 (1988) 110 pp.

[53] F. Amelung, S. Jonsson, H. Zebker, P. Segall, Widespread uplift and 'trapdoor' faulting on Galapagos volcanoes observed with radar interferometry, Nature 407 (2000) 993-996. 